\title{
Seis personagens à procura de um tradutor (ou de um crítico). Por uma história das traduções de Machado de Assis na Itália como história das não traduções: os romances
}

\author{
Six characters in search of a translator (or of a critic). For a \\ history of Machado de Assis' translations in Italy as a history of \\ non-translations
}

Roberto Mulinacci

Universidade de Bologna, Bologna / Itália

roberto.mulinacci@unibo.it

Resumo: Este artigo pretende debruçar-se sobre as dinâmicas editoriais da tradução dos romances de Machado de Assis na Itália, cuja característica dominante é, sem dúvida, representada pela prática da retradução, à qual estão periodicamente submetidas as três obras maiores (Memórias póstumas, Quincas Borba, Dom Casmurro) em detrimento de todas as demais. Portanto, se levarmos em conta que as pouquíssimas traduções não pertencentes à trilogia são bastante negligenciadas pela crítica que se ocupa da recepção do autor e, além disso, nem sequer todas as traduções da trilogia cabem no cânone italiano dele, talvez não seja impróprio perspectivar a história da bibliografia machadiana na Itália pela ótica dos seus vazios, sendo as não traduções a face oculta dos textos efetivamente existentes.

Palavras-chave: Machado de Assis; Itália; retradução; não tradução; cânone; recepção. 
Abstract: This article outlines the translation history of Machado de Assis' novels in Italy, whose main feature is without a doubt the retranslation process, which focuses mainly on the three masterpieces of the writer (Memórias póstumas, Quincas Borba, Dom Casmurro) at the expense of his other works. Therefore, if we consider that the other translations are rather neglected by critics and that not every translation of the trilogy is included in the Machado's Italian canon, perhaps it's not improper to examine the history of Machado's bibliography in Italy from the perspective of its gaps, as the non-translations are the hidden face of the actually existing texts.

Keywords: Machado de Assis; Italy; retranslation; non-translation; canon; reception.

Recebido em 13 de abril de 2016.

Aprovado em 3 de maio de 2016.

\begin{abstract}
Mas, se todo o mal está nisto!... Nas palavras. Todos trazemos dentro de nós um mundo de coisas: cada qual tem o seu mundo de coisas! E como podemos entender-nos, senhor, se, nas palavras que digo, ponho o sentido e o valor das coisas como são dentro de mim, enquanto quem as ouve lhes dá, inevitavelmente, o sentido e o valor que elas têm para ele, no mundo que traz consigo? Pensamos entender-nos... e jamais nos entendemos! ${ }^{1}$
\end{abstract}

Ao contrário da história da economia, da literatura ou do cinema (entre tantos outros), uma história da tradução é um verdadeiro u-topos. [...] A definição do objecto a historiografar está longe de ser óbvia. O facto da instabilidade histórica do conceito de tradução é uma redundância, já que é essa mesma instabilidade que justificaria acompanhar o seu percurso através dos tempos e das circunstâncias. [...] Pergunta-se então: do que é que falamos exactamente quando falamos de tradução?

${ }^{1}$ PIRANDELLO, Luigi. Seis personagens à procura de um autor. 
Dos textos? Da actividade? Da teoria? Dos métodos? Do ensino? Dos tradutores? [...] O trabalho arqueológico é apenas um começo. [...] Entretanto, o fenómeno da nãotradução vai sendo também objecto de interesse. [...] O que, afinal, ressalta deste fenómeno é paradoxal: pode ser tão interessante estudar o que foi como o que não foi traduzido. Poderemos imaginar uma história da tradução como uma história da não-tradução? (SERUYA, 2013, p. 16-17)

Ressurreição, A mão e a luva, Iaiá Garcia, Esaú e Jacó. E, além disso, "Trio em lá menor", "O dicionário", "O caso da vara", "D. Paula", "Suje-se gordo!", "Entre santos", "Um erradio", "Ernesto de Tal", etc. são apenas alguns dos romances e contos de Machado de Assis que os leitores italianos não tiveram até agora a oportunidade de ler na sua própria língua, nem sei, francamente, se terão essa oportunidade no futuro. Em compensação, eles poderiam - caso tenham tempo para vasculhar bibliotecas e sebos e a sorte de encontrá-las ainda à disposição nas prateleiras, sejam reais, sejam virtuais - se entreter com diversas edições dos mesmos textos, por exemplo, as cinco traduções das Memórias póstumas e de Dom Casmurro ou as quatro de Quincas $B o r b a$, para não mencionar mais quatro versões de "O alienista" ou as retraduções de inúmeros outros contos, de "O espelho" a "Missa do Galo", de "Um homem célebre" a "Último capítulo".

Bem-vindos às políticas tradutórias estapafúrdias do mercado editorial italiano! Um mercado que, conforme se depreende dessas sintéticas informações, parece preferir as aparentes certezas dos caminhos já trilhados às igualmente aparentes incertezas dos novos, pelo menos quando se trata de autores "periféricos", embora de porte sem dúvida universal, como, justamente, Machado de Assis. Entendamo-nos: é óbvio que, levando em conta os espaços mercadológicos cada vez mais reduzidos do setor livreiro italiano, uma editora que investe em figuras ainda pouco conhecidas da assim chamada República Mundial das Letras pretende proporcionar ao seu público principalmente as obras-primas delas, com boa paz de qualquer razão de completude e diversificação da

\footnotetext{
${ }^{2}$ Devido à ingente quantidade de dados coletados, resolvi focalizar este estudo apenas nos romances, adiando a sua natural continuação, relativa à produção contística de Machado, para outra ocasião.
} 
oferta. Nesse sentido, não nego que, independentemente de todo juízo de valor, ter em catálogo as Memórias póstumas ou Dom Casmurro seja melhor do que ter Ressurreição ou Iaiá Garcia. Mas o raciocínio está correto só em parte. Com efeito, se considerarmos que algumas dessas editoras que publicam Machado na Itália são infelizmente quase "semiclandestinas", sendo praticamente impossível encontrar seus produtos à venda nas livrarias, o que na realidade pode acontecer é que o leitor eventualmente interessado na leitura do Bruxo do Cosme Velho se dirija diretamente às bibliotecas, onde, contudo, a maioria das edições machadianas presentes são, via de regra, as mais antigas, em particular aquelas dos anos 1950/60 e não, salvo raras exceções, as últimas por ordem de aparição. Isso é, aliás, facilmente explicável: de fato, se uma biblioteca tem já no seu acervo uma versão qualquer da obra de Machado não vai decerto adquirir a sua suposta atualização, por inovadora e oportuna que seja. Eis por que eu acho que, no tocante ao autor em apreço, a escolha de retraduzir seus clássicos mais famosos, ao invés de apostar no ineditismo das obras "menores", se revela, no final das contas, bastante errada, não apenas em termos culturais, como também estratégicos, uma vez que essa proliferação dos mesmos títulos acaba paradoxalmente restringindo o leque de opções à disposição do público estrangeiro e, por conseguinte, diminui as possibilidades de circulação dos textos.

Dir-se-á, dentro da vulgata tradutológica, que as retraduções são, no fundo, necessárias porque as traduções envelhecem e é preciso portanto readequá-las linguisticamente ao nosso horizonte de expectativa, mas a fraqueza desse argumento está mais do que patente se olharmos exatamente para as novas edições machadianas saídas na Itália nos últimos anos, as quais, em geral, não deram grandes passos à frente nesse ponto de vista ou, quando muito, se limitaram a pequenos ajustes pouco significativos, senão decididamente discutíveis, em relação aos seus antecessores.

Vejam-se, a mero título de ilustração, três versões do incipit de Quincas Borba em sequência cronológica, desde a primeira, de Giuseppe 
Alpi, de 1930, ${ }^{3}$ até a última, de Valentina Manzo, de 2012, ${ }^{4}$ passando pela intermediária, de Laura Marchiori, que remonta a 1967:5

\section{Machado de Assis, 1891:}

Rubião fitava a enseada, - eram oito horas da manhã. Quem o visse, com os polegares metidos no cordão do chambre, à janela de uma grande casa de Botafogo, cuidaria que ele admirava aquele pedaço de água quieta; mas, em verdade, vos digo que pensava em outra coisa. Cotejava o passado com o presente. Que era há um ano? Professor. Que é agora? Capitalista. Olha para si, para as chinelas (umas chinelas de Túnis, que lhe deu recente amigo, Cristiano Palha), para a casa, para o jardim, para a enseada, para os morros e para o céu; e tudo, desde as chinelas até o céu, tudo entra na mesma sensação de propriedade.

- Vejam como Deus escreve direito por linhas tortas, pensa ele. Se mana Piedade tem casado com Quincas Borba, apenas me daria uma esperança colateral. Não casou; ambos morreram, e aqui está tudo comigo; de modo que o que parecia uma desgraça...

\section{Giuseppe Alpi, 1930:}

Rubiano fissava quella insenatura del mare. Erano le otto del mattino. Chi l'avesse visto, coi pollici infilati nei cordoni della veste da camera, alla finestra d'una grande

${ }^{3}$ Essa tradução de Alpi, intitulada Gioachin Borba (ASSIS, 1930), seria republicada em 1934, absolutamente idêntica, mas com um novo título, La fortuna di Rubiano (ASSIS, 1934), provavelmente considerado mais atrativo.

${ }^{4}$ Vale ressaltar que esta edição, com um paratexto reduzido ao osso (apenas duas orelhas, onde se encontram um resumo do romance e umas sinteticíssimas informações sobre o autor), apareceu em uma coleção intitulada ArCani, que, conforme diz o nome, é devotada à publicação de livros relativos aos cachorros, dos guias de raças a narrativas protagonizadas por cães (cf. ASSIS, 2012).

${ }^{5}$ ASSIS, 1967. 
casa di Botafogo, avrebbe creduto che ammirasse quella superficie di acqua tranquilla; ma vi dico, in verità, che pensava a ben altro. Paragonava il passato col presente. Che era egli mai un anno prima? Un maestrucolo. Che è oggi? Un capitalista. Esamina bene sé stesso, guarda le sue babbucce (certe babbucce di Tunisi, che gli ha regalate un nuovo amico, Cristiano Paglia), guarda la casa e il giardino, la baia, i colli e il cielo; e tutto, dalle babbucce al cielo, è compreso in quel medesimo sentimento di proprietà.

- Ecco come Dio provvede con i mezzi più inaspettati pensa. - Se mia sorella Pietà avesse sposato Giachin Borba, mi avrebbe lasciato appena una speranza collaterale. Non lo sposò; sono morti ambedue e tutto è rimasto a me; sicché quel che pareva una disgrazia... (ASSIS, 1930, p. 9).

\section{Laura Marchiori, 1967:}

Rubião contemplava la baia; erano le otto del mattino. Chi lo avesse visto, coi pollici infilati nel cordone della veste da camera, alla finestra di un vasto edificio nel quartiere di Botafogo, avrebbe creduto che egli stesse ammirando quel tratto di oceano tranquillo; ma vi dico sinceramente che egli pensava ad altro. Confrontava il passato col presente. Che cosa era lui un anno prima? Un professore. Che cos'è oggi? Un capitalista. Rubião volge lo sguardo sulla sua persona, sulle pantofole (certe ciabatte tunisine, regalategli da un amico di data recente, Cristiano Palha), guarda la casa, il giardino, la baia, i colli, il cielo; e tutto, dalle pantofole sino al cielo, è compreso nella stessa sensazione di possesso."'Guardate un po' come non tutto il male viene per nuocere" pensa Rubião. "Se mia sorella Piedade avesse sposato Quincas Borba, mi avrebbe dato soltanto la speranza di una eredità in linea collaterale. Non si è sposata; sono morti entrambi, ed ecco che tutto è in mio possesso. Perciò quella che sembrava una disgrazia... (ASSIS, 1967, p. 15). 


\section{Valentina Manzo, 2012:}

Rubiano fissava quella insenatura del mare. Erano le otto del mattino. Chi l'avesse visto, mentre teneva i pollici infilati nei cordoni della vestaglia, affacciato alla finestra di una grande casa di Botafogo, avrebbe creduto che stesse ammirando quella superficie di acqua tranquilla; ma io vi assicuro che in realtà pensava a ben altro. Confrontava il passato con il presente. Cos'era mai lui soltanto un anno prima? Un maestro da due soldi. E cos'è ora? Un imprenditore. Si osserva con attenzione; guarda le sue pantofole (delle pantofole che venivano da Tunisi, che gli aveva regalato Cristiano Paglia, un suo nuovo amico); guarda la casa, il giardino, la baia, i colli e il cielo; e tutto, dalle pantofole al cielo, entrava a far parte di quel medesimo sentimento di proprietà.

"Ecco come Dio ci viene in soccorso con i mezzi più inaspettati", pensò. "Se mia sorella avesse sposato Gioachin Borba, mi avrebbe lasciato appena una speranza di seconda categoria. Non la sposò; sono morti entrambi e tutto è rimasto a me; da ciò ne viene che quella che sembrava una sfortuna... (ASSIS, 2012, p. 3).

Pois bem, como fica sobejamente evidente, a versão de Manzo não é nada mais do que uma cópia em linha reta daquela de Alpi, da qual, na contramão de toda prática tradutória minimamente sintonizada com os avanços da sua área disciplinar, retoma, dentre outras coisas, também o velho hábito de traduzir os nomes, atrasando assim os ponteiros da tradutologia italiana em pelo menos meio século. De resto, as variantes lexicais propostas por essa recentíssima tradução são mínimas em termos quantitativos (vestaglia no lugar de veste da camera, pantofole no de babbucce, sfortuna no de disgrazia) e, em alguns casos, bem piores em termos qualitativos (imprenditore é, com efeito, uma atualização abusiva de capitalista, do mesmo modo que di seconda categoria constitui um abuso semântico a respeito de collaterale), contribuindo, pois, para confirmar a impressão de uma substancial falta de progressos na cadeia diacrônica em pauta. Uma impressão, aliás, que não é questionada nem 
pela terceira versão desse aparente continuum tradutório, a de Marchiori, a qual, se, de um lado, apresenta visíveis traços evolutivos face às suas duas extremidades (a partir, justamente, da manutenção dos nomes na língua original), de outro lado, esconde debaixo da superfície inegáveis tendências involutivas, tais como as descritas - ou implicitamente sugeridas - por Antoine Berman (2007) sob o rótulo de "tendências deformadoras", a saber: "alongamento" (quartiere di Botafogo por Botafogo, speranza di un'eredità in linea collaterale por speranza collaterale), "clarificação" (oceano por acqua), "enobrecimento" (vasto edificio em vez de grande casa), "enriquecimento quantitativo" (duas palavras, pantofole e ciabatte, para traduzir um único significante, chinelas), e, para finalizar, a "destruição das locuções", segundo demonstra o provérbio Deus escreve direito por linhas tortas, vertido para o italiano mediante o recurso a uma equivalência absolutamente imprópria como non tutto il male viene per nuocere (= "há males que vêm para o bem").

Em suma, se talvez esse exemplo de Quincas Borba - e os demais que eu poderia citar, retirados também de outras obras ${ }^{7}$ - não chegue a desmentir por completo a afirmativa de Berman (2007, p. 97) de que é no espaço da retradução "que geralmente a tradução produz suas obras-primas", com certeza, porém, aponta para a dificuldade de se interpretar a história das traduções machadianas na Itália em chave teleológica, enquanto movimento ascendente e progressivo para um padrão de adequação linguístico-textual consubstanciado em um único texto alvo. Aliás, deixando de lado a circunstância de todas as "segundas traduções" (BERMAN, 2007, p. 97) se assemelharem bastante e de a maioria das suas diferenças serem, não raro, irrelevantes para o leitor

\footnotetext{
${ }^{6}$ Batizo aqui, por analogia, como "enriquecimento quantitativo" o inverso do que Berman (2007, p. 54) chama de "empobrecimento quantitativo", ou seja, o "desperdício lexical" que se tem quando há "menos significantes na tradução que no original". Neste caso, portanto, o "enriquecimento" indica obviamente a situação contrária, vale dizer, a presença no texto-alvo - em virtude sobretudo de uma inoportuna variação sinonímica - de um número de equivalentes tradutórios maior que o das palavras do texto-fonte. ${ }^{7}$ Penso, em particular, na genealogia das traduções das Memórias póstumas, cuja última "flor", de autoria de Silvia Marianecci, desabrochou em 2005 com um título bem estranho, embora obviamente machadiano, como Marcela mi amò per quindici mesi e undicimila scudi, niente meno (Roma, Azimut). Além do título, no entanto, são muitas as perplexidades suscitadas por essa empreitada editorial.
} 
italiano, em que deveria assentar a identificação desse padrão modelar? Em um estéril cotejo de trechos selecionados, conduzindo, no final das contas, a insossas listinhas de variantes, capazes tão só de comprovar comportamentos tradutórios nem sempre superponíveis?

Mas, então, se, pelo que parece, a lógica da retradução não está justificada por nenhuma intervenção radical em nível de texto, nem tampouco por projetos editoriais visando efetivamente uma maior popularização das obras canônicas do escritor brasileiro, qual o motivo real para insistir nessa estratégia literária? Apenas um motivo estético, isto é, ligado ao gosto pessoal de cada tradutor? E quanto influi, embora porventura inconscientemente, ${ }^{8} \mathrm{o}$ fato de os retradutores se sentirem de certa forma amparados pela experiência dos colegas, a ponto de preferirem se colocar na esteira deles a aceitar o desafio de uma autêntica emulação antagônica, decorrente daquela espécie de bloomiana anxiety of influence? Ou não será, ao contrário, que, além do debate em torno dos aspectos etiológicos das retraduções, para onde convergem sem dúvida todos os fatores acima citados, o verdadeiro âmago da questão concerne principalmente ao fenômeno da não tradução, de que a retradução é, afinal, apenas um efeito ao invés de uma causa? Em outras palavras, uma pergunta útil para nos apercebermos das características peculiares da (des)fortuna da obra machadiana na Itália não é "por que se retraduz?" e sim “por que não se traduz?", levando em conta que, nesse caso, uma tal política da não tradução foge àquelas categorias explanatórias propostas, por exemplo, em um ensaio merecidamente famoso, por Duarte $(2000)^{9} \mathrm{e}$

\footnotetext{
${ }^{8}$ Decerto, contudo, não é inconsciente a relação que liga os tradutores da penúltima versão de Dom Casmurro (ASSIS, 1997), Gianluca Manzi e Léa Nachbin, a Laura Marchiori, uma vez que, na "Nota biobibliografica" final (ASSIS, 1997, p. 294), Manzi faz questão de agradecer pessoalmente à tradução dela (edição original de 1958, depois reimpressa em 1991) por lhes ter servido frequentemente de guia para dissipar suas dúvidas. A esse propósito, Salomão (2011, p. 29) considera a tradução de 1997 apenas uma "cópia com pequenas mudanças" da de 1958, falando até de "uma situação, praticamente, de plágio", ao passo que Olmi (2001), autora de um estudo sobre as duas versões italianas em apreço, tem uma opinião totalmente diferente, deixando transparecer, nas entrelinhas, sua ligeira, mas firme predileção pelo trabalho de Manzi e Nachbin.

${ }^{9}$ Refiro-me, em particular, além de a language closeness e bilingualism, na Itália
} 
hoje em dia todas mais ou menos inaplicáveis a esse contexto específico, com as únicas exceções da omission e repetition. Ou seja, não há nada, claro, de ideológica ou axiologicamente controverso em Machado de Assis que não possa ser levado ao conhecimento do público italiano, mas, apesar disso, quatro romances de um conjunto de nove e mais de 150 contos de um conjunto de cerca de duzentos continuam inéditos na Itália, ainda que o maior autor brasileiro de todos os tempos esteja maciçamente presente nesse polissistema literário nacional há quase noventa anos, desde 1928.

A explicação para o ostracismo a que a patronagem do meu país tem historicamente condenado uma parte não secundária da produção do nosso autor pode provavelmente ser encontrada na não funcionalidade ou, se quisermos, até na contraprodutividade - dos textos não traduzidos para a construção de um cânone italiano de Machado de Assis, uma vez que esse cânone não só não coincide in toto com o construído pela cultura de origem, sendo evidentemente parcial em relação a ele, como também ultrapassa os próprios limites do que é o discurso sobre a literatura brasileira na Itália, apresentando, para tomar emprestada a terminologia de Eco (2011, p. 40), uma diferente segmentação da sua matéria do conteúdo. Dito de outro modo: se é natural que a seleção dos textos a serem traduzidos esteja mais em conformidade com os valores estéticos da cultura de chegada do que com aqueles da cultura de partida (cf. VENUTI, 1998, p. 195-196), talvez seja menos natural - e, por isso, mais interessante, quando observado pelo nosso ângulo - que os valores estéticos usados para canonizar localmente um escritor (sob certos aspectos, um verdadeiro processo de localização ${ }^{10}$ ) se diferenciem consideravelmente daqueles tidos como pertinentes para a imagem local,

completamente não pertinentes, a cultural distance, institutionalised censorship, ideological embargo, cuja pertinência, pelo contrário, precisa ser relativizada consoante as várias épocas históricas (e, de resto, não é à toa que o case study analisado por Duarte diga respeito à recepção das traduções de Shakespeare no Portugal da última década do século XIX).

${ }^{10}$ Uso aqui o termo técnico de localização enquanto "tradução e adaptação de um software para comercialização em um mercado específico" (RIBEIRO, 2005, p. 234), para indicar lato sensu os processos de adaptação sofridos também pelas obras literárias na sua circulação internacional, mas sem nenhuma conotação particularmente abusiva, visto que na nossa sociedade contemporânea multimidiática os sites das editoras subjazem às mesmas leis do mercado que valem para outros produtos tecnológicos. 
diversa de país para país, da cultura a que ele pertence. Nesse sentido, o discurso italiano sobre Machado não se revela coextensivo ao discurso italiano sobre a literatura brasileira em geral, na medida em que os traços identitários tradicionalmente atribuídos a ela por esta específica indústria cultural, sobretudo no passado, não são os mesmos prevalecentes no retrato dele que se tem vindo a esboçar ao longo de um século nos vários paratextos editoriais. Com efeito, em lugar do exotismo, antes misterioso e ameaçador e depois cada vez mais pitoresco e sensual, que permeia as primeiras fases da recepção do Brasil literário na Itália (cf. MULINACCI, 2015), registra-se, no caso de Machado, uma ausência quase total de leituras exotizantes, da qual se acompanha inclusive uma atitude crítica de gradual desnacionalização do seu objeto, visando universalizar o alcance da obra desse gênio brasileiro, a despeito, justamente, do Brasil.

Não é de se estranhar, então, que, após sua estreia, em 1928, graças à tradução das Memórias póstumas levada a cabo por Mario da Silva e na qual comparecem ainda as marcas culturais de uma brasilidade reivindicada com orgulho, até em perspectiva antilusitana, ${ }^{11} \mathrm{o}$ Machado italiano venha progressivamente sobrepondo a essas roupagens nacionais a feição de um escritor profundamente internacional, tanto pelos modelos da sua escrita (de Montaigne a Shakespeare, de Cervantes a Swift, de Sterne a Schopenauer), quanto pela grandeza do seu valor, ao menos de estatura continental, conforme realça Giuseppe Alpi, que, na nota ao leitor anteposta à versão supramencionada de Quincas Borba, o define, não por acaso, "il più profondo dell'America latina" (ASSIS, 1930). Um juízo implicitamente comparativo este, que além de ser legítimo e sem dúvida compartilhável, seria absolutamente normal em um texto de acompanhamento procurando fornecer balizas capazes de orientar o público estrangeiro, se não fosse, porém, a falta ali de toda e qualquer

11 "Memorie di Braz Cubas [...] sono a tutt'oggi il più originale e umano romanzo che possegga la letteratura brasiliana e uno fra i più profondi di tutta la letteratura della lingua portoghese; certamente superiore ai romanzi di Eça de Queiroz, più scintillante ma più superficiale, che per qualche tempo fu considerato il rivale d'oltreoceano di Machado de Assis, fra gli scrittori di lingua portoghese" ("As Memorie di Braz Cubas são hoje em dia o romance mais original e humano que tem a literatura brasileira e um dos mais profundos de toda a literatura em língua portuguesa; ele é com certeza superior aos romances de Eça de Queiroz, o qual, mais brilhante mas mais superficial, foi considerado por algum tempo, entre os escritores de língua portuguesa, o rival d'além-mar de Machado de Assis') (ASSIS, 1928, p. 7, tradução minha). 
referência ao Brasil ou simplesmente à nacionalidade brasileira de Machado, tirante um pequeno parêntese com a indicação do Rio de Janeiro como lugar de seu nascimento e morte. É verdade que, para todas as notícias sobre a vida e a obra do Bruxo do Cosme Velho, Alpi remete o leitor à introdução das Memórias póstumas, obra por ele traduzida no ano anterior (cf. ASSIS, 1929), mas não deixa de ser curioso que quem se deparasse com este Gioachin Borba. L'uomo o il cane? sem ter lido o outro romance, estivesse desprovido da mínima informação a respeito de uma tal figura de "artista e filósofo", cuja obra parecia suscitar tanto interesse.

Assim como igualmente curioso é que Alpi justifique seu "excessivo" escrúpulo tradutório precisamente em nome dessa grandeza do escritor ${ }^{12}$ - sancionada, de resto, também pela opinião autorizada de Carlos Magalhães de Azeredo, na abertura da nota em apreço -, embora seja difícil, senão como exercício contrafactual, dizer em que consiste concretamente essa suposta acribia filológica do tradutor italiano e, ainda mais, o que ele entende por aqueles "pormenores" passíveis de serem omitidos sem demasiados problemas. O que interessa saber, contudo, é que, descontando as convenções tradutórias, aqui inevitavelmente marcadas, como a língua, pela usura do tempo, os preceitos de "fidelidade quase absoluta" nos quais Alpi afirma ter inspirado seu trabalho podem considerar-se, grosso modo, cumpridos, em particular no que se refere ao cuidado especial pelos dados culturais, que, expulsados pela porta do peritexto, acabavam agora inesperadamente reentrando pela janela. Só que, longe de estar em contradição com a tese da universalização de Machado por mim aventada, as numerosas notas de rodapé que pontilham essa versão italiana de Quincas Borba, debruçando-se sobre o meio histórico-geográfico evocado pela narração, representam, na realidade,

12 "In considerazione della grandezza dell' artista e del filosofo, abbiamo voluto tradurre il presente romanzo con uno scrupolo che a qualcuno parrà, e forse non senza ragione, eccessivo: anche in particolari in cui avremmo potuto ben correre o sorvolare. Abbiamo detto il perché: trattandosi di grandi, una fedeltà quasi assoluta al testo non pare possa mai considerarsi pedantesca" ("Levando em consideração a grandeza do artista e do filósofo, quisemos traduzir este romance dum modo tão escrupuloso que pode parecer a alguém, e talvez não sem razão, excessivo, mesmo no tocante aos pormenores de que poderíamos ter passado tranquilamente por cima. Já dissemos porquê: tratando-se de grandes autores, uma fidelidade quase absoluta ao texto nunca pode parecer pedantesca') (ASSIS, 1930, tradução minha). 
uma confirmação indireta do processo, uma vez que a presença delas garante justamente aquela plena fruição do texto necessária para o fazer circular pelo mundo afora.

Se, em suma, interpretando Alpi, as sutilezas linguísticas e os elementos culturais não passam de entraves a caminho do reconhecimento internacional que se espera para o escritor, caberá, no entanto, a Laura Marchiori a tarefa de contribuir para a efetivação dessa meta, delineando um primeiro cânone italiano da obra machadiana destinado a resistir, sem grandes mudanças, até quase os nossos dias. ${ }^{13}$ De fato, em uma série de três notas introdutórias, repetidas praticamente idênticas - a não ser pelos acréscimos contingentes - na sua tradução da trilogia, que vem a lume entre 1953 e $1967^{14}$ sob a chancela da histórica coleção Biblioteca Universale da editora Rizzoli, de Milão, Marchiori não se limita a ressaltar a "mensagem de universalidade" proveniente das páginas do autor e suficiente, no entender dela, para o colocar no olimpo da literatura mundial, mas, na esteira de Alpi, traça também as fronteiras externas desse corpus, recortando um centro, identificado naturalmente com os três romances maiores, à volta do qual estão as vastas periferias da restante produção, atingida pelos "estigmas" do idealismo românticosentimental. Com efeito, ao julgar "medíocres e falsos" (ASSIS, 1967, p. 7) os romances da primeira fase machadiana e eivado de "fraco sentimentalismo" (ASSIS, 1967, p. 11) o último título, o Memorial de Aires, a tradutora italiana participa daquela exegese canonizadora dominante, visando manipular a recepção de Machado na Itália em função desta única faceta realista e universal, que terminaria por se

${ }^{13}$ Esse horizonte estreito do cânone machadiano, fundamentalmente antirromântico, sofreu uma primeira ampliação só em 1986 com o Memoriale di Aires - reimpresso em 2009 pela Lindau, na mesma versão de Giuliana Segre Giorgi -, a que se seguiria, vinte anos depois, a edição original de Helena, publicada em Nápoles pela editora Liguori e com tradução ao lado para o italiano devida a Carla Cirillo. Entretanto, além dos contos, de que me vou ocupar em outro momento, e inclusive dos poemas, de que saíram em 2014 duas coletâneas (Crisalidi e Falene), editadas ambas pelas Edizioni Kolibris com tradução de Chiara De Luca, é sem dúvida Helena a verdadeira novidade nessa canonização italiana de Machado, dado que - diferentemente do que faz Segre Giorgi no posfácio do Memoriale di Aires - a organizadora do volume, Maria Luisa Cusati, se põe de modo declarado na contramão do modelo anterior, ao destacar, na breve introdução, exatamente o atrativo e a validade da construção romântica do enredo. ${ }^{14}$ Memorie dall'aldilà (1953), Don Casmurro (1958) e Quincas Borba (1967). 
impor naquele público-alvo como emblemático contraponto de uma certa imagem estereotípica do Brasil e para cuja inquestionada reprodução, ao longo dos anos, era, portanto, preciso não traduzir os textos "menores", mais do que simplesmente retraduzir as obras-primas.

Entretanto, se, como vimos, vai demorar muito tempo até que esse padrão canonizado integre novos textos, possibilitando, não digo contraleituras, mas apenas leituras mais abrangentes, talvez valha a pena lembrar que a própria leitura canonizante de Marchiori, aparentemente monolítica e fixa, não está, na verdade, isenta de desvios e contradições, deixando entrever, na passagem de uma tradução para outra, interessantes reposicionamentos críticos e metodológicos. Basta observar, por exemplo, como muda, no intervalo de tempo que medeia entre as duas versões de Don Casmurro e Quincas Borba, a avaliação do Esaú e Jacó, cujo óbvio e constante enquadramento no grupo das obrasprimas machadianas não impede a tradutora de o definir - na "Nota" à edição de Quincas Borba - "um romance nebuloso, de um simbolismo requintado" (ASSIS, 1967, p. 11, tradução minha) ${ }^{15}$, encarnando, segundo ela, aquela involução que, ali já incipiente, se manifestaria em grau máximo no supracitado "fraco sentimentalismo" do Memorial de Aires. Mas muito mais do que por esta nuança exegética - de qualquer maneira, porém, não insignificante, se levarmos em conta que das quatro obras-primas reconhecidas por Marchiori o Esaú e Jacó será a única a não ser vertida para o italiano -, a tradução de Quincas Borba de 1967 merece ser destacada sobretudo pela adoção sistemática de uma diferente estratégia tradutória, menos virtualmente "anexionista" em relação aos trabalhos precedentes, conforme demonstra em especial o respeito pelos nomes originais dos lugares e dos personagens. Chega de Biagio Cubas e Pasquina, de via del Pidocchio e piazza della Gloria, de Benedetto e zio Cosimo, mas chega também daquelas incongruências ainda mais gritantes como Bentinho e Pietro de Albuquerque, Josè $\grave{16}^{16}$ Dias e Sancia, via delle

\footnotetext{
15 "un romanzo brumoso, di un simbolismo ricercato".

${ }^{16} \mathrm{O}$ acento grave, ao invés de agudo, que traz o nome José nessa versão de Marchiori se deve provavelmente a uma adaptação ao sistema fonético do italiano, que, de outro modo, levaria o leitor a pronunciar a sílaba tônica como vogal fechada e não aberta. Mas o escrúpulo vocálico choca-se com o problema consonantal da pronúncia do $j$, cuja realização mais imediata, por influxo do espanhol, seria uma fricativa gutural surda.
} 
Viole e via do Ouvidor, as quais, na oscilação entre a forma portuguesa e a sua italianização, denunciam a transição em ato rumo a uma poética tradutória mais moderna, de que Quincas Borba representaria um dos primeiros modelos, logo a seguir ao Don Casmurro de Liliana Borla, publicado em 1954.

É esta última, com efeito, a edição que marca um ideal divisor de águas na história editorial de Machado na Itália, visto que, pela primeira vez, se propõe uma tradução realmente preocupada com os valores linguísticos e culturais do texto de partida, e cuja especificidade - ressalvados uns casos particulares e deixando-se de lado a avaliação do resultado geral - parece estar subtraída à tentação etnocêntrica da normalização. Tomem-se, por exemplo, além da questão onomástica, assente aqui na tendencial preservação dos nomes próprios, embora com alguns incompreensíveis desvios (Ezechiele por Ezequiel), também o processo de transferência dos realia, submetido ao mesmo afã conservador, que relega às notas de rodapé os eventuais excessos semânticos não "geríveis" intratextualmente pela lógica da equivalência. Eis, portanto, projetada contra o pano de fundo de uma tradição tradutória até então naturalizante, a opção de Borla em favor da não tradução de termos culturais específicos como Dona (que Marchiori traduz, com diverso matiz sociolinguístico, por Donna), conto (que Marchiori traduz por scudi, ${ }^{17}$ trocando o Brasil por Portugal), nhô (forma aferética de senhor, que Marchiori traduz pela variante dialetal sor) ou o topônimo serra dos Órgãos (que Marchiori traduz pelo sintagma híbrido monti Órgãos) - todos devidamente explicados nas notas de rodapé -, ao passo que outros termos como agregado ou moleques, dois clássicos problemas da análise tradutológica português-italiano, encontram ali seus menos inadequados equivalentes em famiglio $^{18}$ e monelli (ao invés

${ }^{17}$ A esse propósito, chama a atenção que, arrebatada pelas exigências do multiculturalismo, Marchiori, na sua tradução de Quincas Borba, transforme estes scudi em franchi, resultado, salvo engano, da influência da cultura francesa na sociedade italiana da época.

${ }^{18}$ Concordo completamente com Salomão (2011, p. 33) sobre a oportunidade de manter agregado em português, evitando transposições reducionistas, mas acho que, em comparação com as alternativas propostas pelos demais tradutores, o famiglio de Borla, remetendo etimologicamente também a uma ideia de família declinada em termos de dependência (como a que se dava com os trabalhadores rurais da Itália do Norte), é talvez uma aproximação menos aproximativa. 
de, respectivamente, parassita e negri, como em Marchiori).

Todavia, apesar da apreciável qualidade global dessa operação tradutória, que não se presta, decerto, para elogios exagerados, mas que nem sequer faz sentido menosprezar, o Don Casmurro de Borla fica bastante à margem da bibliografia especializada sobre o tema em pauta, se configurando como um puro parêntese naquela sucessão italiana dos livros de Machado que vai das versões de Alpi para as de Marchiori e daí chega até as suas últimas ramificações contemporâneas. Não tem bastado, para lhe dar visibilidade, que essa tradução tenha sido publicada por uma das principais editoras da época (Fratelli Bocca Editori), em uma coleção de nome Biblioteca Mondiale Bocca, que tinha inclusive uma espécie de subcoleção de Scrittori Brasiliani, da qual já faziam parte autores como Graciliano Ramos, Manuel Antônio de Almeida e Sérgio Buarque de Holanda e à qual se incorporariam, posteriormente, também Ciro dos Anjos, Gilberto Freyre, Lins do Rego e Simões Lopes Neto: em suma, o quanto de melhor a Itália dos meados do século XX poderia oferecer para a divulgação da literatura brasileira. Qual, então, a causa dessa (semi-)invisibilidade da referida tradutora, posto que, repito, não pode ser explicada pela própria incompetência dela ${ }^{19}$ nem pelos defeitos intrínsecos do produto final, exceto porventura a ausência de um texto de apresentação?

Provavelmente, estamos aqui diante de uma daquelas assimetrias tão marcadas entre explanandum quantitativo e explanans qualitativo que, como sugere Franco Moretti (2005, p. 37), a verdadeira descoberta consiste apenas no levantamento do problema a ser pesquisado, ainda que não se tenha nenhuma ideia de como solucioná-lo. Uma coisa, no entanto, é possível dizer: o Don Casmurro de 1954 permite, ao menos, antecipar a entrada em voga de uma postura tradutória mais comprometida com o respeito pela alteridade cultural e de que, pelo contrário, Rita Desti, na sua versão das Memórias póstumas de 1983, parecia se considerar quase

${ }^{19}$ Se, conforme defende Anthony Pym, cuja postura é sintetizada por Seruya (2013, p. 19), "o objecto central do conhecimento histórico sobre tradução não é o texto, nem o contexto, nem as características linguísticas, mas sim o "tradutor humano", é importante frisar que, quando saiu a sua tradução de Dom Casmurro, Liliana Borla já tinha publicado, em parceria com Bruno di Valmartina, um manual de conversação para a aprendizagem do português na Itália intitulado Parliamo portoghese: così si parla in Brasile (Firenze, Edizioni Le Lingue Estere, 1946). 
uma precursora no âmbito da verbalização de Machado em italiano, ${ }^{20}$ esquecendo assim, além da lição de Borla, até aquela da própria Marchiori (cf. ASSIS, 1967). Esta é, de resto, a outra face do cânone, o qual não se alimenta somente de traduções e não traduções, mas também de traduções tidas em conta de não traduções, isto é, ignoradas ou recalcadas pela crítica tanto por não se afigurarem condizentes com a representação de um autor ou de uma literatura (dois estudos de caso paradigmáticos são, como vimos, o de Helena e o do Memorial de Aires, ambos bastante negligenciados neste tipo de resenhas acadêmicas) quanto por não se acomodarem perfeitamente ao sistema de convenções e expectativas vigente em um determinado momento ou simplesmente à lógica da conveniência que o embasa. E isso vale, no fundo, seja para Borla, seja para Desti. É, com efeito, bastante elucidativo das modalidades de funcionamento desse sistema que, por trás da anunciada ruptura com os modelos anteriores, em nome da qual ela havia sido justificada, a tradução de Desti, além do meritório restyling linguístico, não se afaste muito das escolhas feitas por Marchiori nas suas Memorie dell'aldilà (cf. SALOMÃO, 2014, p. 31), de forma, afinal, a continuar reafirmando aquela estrutura do sistema que pretendia reformular. ${ }^{21}$

20 "Per quanto me lo consentiva la norma italiana, ho cercato di essere fedele: sintatticamente oltre che lessicalmente. Quanto al lessico, ho conservato molte parole nella loro forma originaria: a cominciare dall'onomastica. Mi è parso che non avesse ormai più senso (se non nei casi di assoluta coincidenza come Marcela-Marcella, Virgília-Virgilia, Prudêncio-Prudenzio, ecc.), in un mondo sempre più piccolo e avvezzo agli scambi internazionali, tradurre Biagio Cubas o Gioacchino Borba o, peggio ancora, rendere in un problematico italiano i nomi dei quartieri e delle strade di Rio de Janeiro che radio e televisione ci divulgano ogni giorno così come essi sono" ("Pelo que me foi permitido pela norma italiana, tentei ser fiel: sintaticamente, além de lexicalmente. Quanto ao léxico, mantive muitas palavras na forma original, a partir da onomástica. Pareceu-me que já não fizesse muito sentido (tirante os casos de absoluta coincidência tais como Marcela-Marcella, Virgília-Virgilia, Prudêncio-Prudenzio, etc.), em um mundo cada vez menor e acostumado aos intercâmbios internacionais, traduzir Biagio Cubas ou Gioacchino Borba ou, pior ainda, verter para um problemático italiano os nomes dos bairros e das ruas do Rio de Janeiro que o rádio e a televisão nos divulgam todo dia assim como eles são') (ASSIS, 1983, p. XI, tradução minha).

${ }^{21}$ Aproveito aqui os dados coletados por Salomão (2014) para demonstrar como entre Memorie dell 'aldilà (1953), traduzido por Marchiori, e Memorie postume di Brás Cubas (1983), traduzido por Desti, as diferenças são mais formais do que conteudísticas, 
Não surpreende, por conseguinte, que a força autoperpetuadora do cânone, pautada antes pelo critério da manutenção do que pelo da revisão, propusesse em 1991, mais uma vez e sempre sob a chancela da Rizzoli, aquela velha tradução das Memorie dell'aldilà de 1953, com as mesmas pechas originais e sem nenhum esforço atualizador, mas emoldurada por uma nova introdução da escritora norte-americana Susan Sontag no lugar da de Marchiori. Destarte, ao apagar de uma vez algumas décadas de progressos teórico-metodológicos, a história da recepção de Machado na Itália voltava, grosso modo, ao seu grau zero, colocando a leitura do "grande realista" sob o signo de uma dupla defasagem, tradutológica e cultural: de um lado, a bem conhecida naturalização linguística da tradução de Marchiori, procurando reduzir a estraneidade da obra em prol da sua legibilidade; de outro, a internacionalização exegética do artigo de Sontag - escrito originalmente para a revista New Yorker, onde apareceu em 1990 e, sobretudo, pensado para um público anglófono -, tendo por objetivo apresentar aos leitores italianos um ignoto autor brasileiro a partir do que se revela, ao olharmos bem, substancialmente uma "reavaliação crítica de Laurence Sterne" (MOREIRA, 2009, p. 98). ${ }^{22}$ Seja como for, uma tal descontextualização de Machado realizada por Sontag, longe de ser uma peculiaridade decorrente de um filtro analítico estrangeiro, vai se tornar uma tônica mesmo nas traduções mais recentes, por exemplo, nas

principalmente no tocante à transposição do vocabulário cultural brasileiro, que, de fato, se repete sem significativas alterações de uma versão para outra. Vejam-se contos, traduzido em ambas por scudi, chácara por villa ou giardino, barata por scarafaggio, mucama por bambinaia, saudade por rimpianto (Marchiori) e nostalgia (Desti), moleques por negri (Marchiori) e negretti (Desti) e, para finalizar, até um tinhorão que de albero tropicale (Marchiori) se converte, em Desti, em um genérico verzura (= vegetação), termo, aliás, bon chic, bon genre, marcado diafásico-diastraticamente no italiano contemporâneo como sendo de estilo muito elevado.

${ }^{22}$ É curioso que outras edições machadianas, nomeadamente a francesa e a estadunidense, compartilhem um destino semelhante a esta edição italiana. Por exemplo, seja a edição francesa de Dom Casmurro de 1997, seja a edição estadunidense das Memórias (Epitaph of a small winner) de 1990 limitam-se a republicar traduções anteriores, a de Francis de Miomandre de 1956 e a de William L. Grossman de 1952, respectivamente. Ademais, ambas as edições são prefaciadas por escritoras de renome - por menor ou maior que seja - tais como Linda Lê, na edição de Albin Michel, e, mais uma vez, Susan Sontag, naquela de Noonday Press. Cf. sobre o assunto TORRES, 2011, p. 51-52; MOREIRA, 2009, p. 99. 
últimas duas de Dom Casmurro - aquela acima já referida, editada pela Fazi em 1997 e de responsabilidade de Gianluca Manzi e Léa Nachbin, e a outra, de Guia Boni, vinda à luz em 2006 -, onde os organizadorestradutores se encarregam de universalizar a mensagem machadiana propondo leituras inovadoras e absolutamente não banais, como, em particular, o belo posfácio de viés psicanalítico assinado por Nachbin (de novo, curiosamente, uma estrangeira, por sinal, oriunda do Brasil).

Só que, enquanto este texto é compensado por uma "Nota biobibliografica" de Manzi acerca da vida e da obra de Machado, com, inclusive, um útil adendo relativo à sinopse histórica das suas edições italianas e um glossário, embora não exclusivamente brasileirocêntrico, de 47 verbetes (de Engenho Novo a gaturamo, de cocadas a voltarete, de Rua dos Barbonos a Gesù Sirac), o aparato paratextual de Boni, abrigado debaixo da capa em estilo gótico apresentando uma pintura de Mino Carta (Fausto no parque Siqueira Campos), não proporciona ao leitor nenhum movimento recontextualizante que o aproxime daquela realidade carioca do final do século XIX tranquilamente transcendida pelo prefácio. Não se trata, escusado será dizer, de questionar a legitimidade dessas abordagens meta-históricas e metaliterárias, sem dúvida apropriadas e às vezes até esclarecedoras, mas apenas de constatar como, diferentemente do que acontece com as traduções de Machado para outras línguas - penso, dentre a ampla casuística possível, principalmente nas traduções inglesas e, em especial, no Dom Casmurro traduzido por John Gledson, uma autêntica mina de informações sobre os processos históricos e sociais subjacentes ao enredo romanesco -, a recepção italiana do autor continua a se concentrar no texto individual, à revelia não só do contexto, como também dos demais textos do corpus considerados no seu conjunto. Deste ponto de vista, se a opção de Boni pela neutralização da maioria das palavras-chave dessa visualização do Rio de Janeiro - as mesmas palavras, aliás, isoladas no glossário de Manzi e Nachbin -, renunciando "à tradução explicativa, geralmente em aposição ou entre parênteses, dentro do tecido textual" (TORRES, 2008, p. 35) e se contentando, em alternativa, com a simples incorporação das formas originais, manifesta a clara intenção de se esquivar de exotizações incongruentes com o projeto editorial, essa própria opção tradutória corre o risco, todavia, de autorizar também, conquanto de maneira indireta, homologações culturais igualmente incongruentes e indevidas. 
Risco, este, que evitado pelo Dom Casmurro de Boni (o único, de resto, desta série diacrônica a trazer louvavelmente o Dom em formato "pré-conversão"), será, pelo contrário, (in)conscientemente assumido, com tudo o mais que isso comporta, pelo Quincas Borba de Manzo, o último contributo italiano - por ora - à difusão internacional de Machado e sobre o qual já me debrucei no início deste ensaio a fim de mostrar os percalços das retraduções. No entanto, se, ao encerrar o meu percurso crítico, volto agora a encarar o assunto, não é em função da categoria de retradução que o faço e sim daquela de não tradução, da qual esta epigônia edição machadiana me parece paradoxalmente um símbolo exemplar. De fato, após as não traduções propriamente ditas e as traduções recalcadas pelo polissistema, o Gioachin Borba. L'uomo o il cane? constitui uma prova cabal da existência das assim chamadas não traduções implícitas, ${ }^{23}$ ou seja, aquelas traduções que não possuem os requisitos mínimos das verdadeiras traduções, se configurando, antes, como adaptações, paráfrases ou, no máximo, meras atualizações linguísticas de traduções alheias. Mas se é este último, literalmente, o espaço dentro do qual se move também o Quincas Borba "retraduzido" por Manzo, que anuncia desde o título a sua filiação à versão de Giuseppe Alpi de 1930 - de que é, repito, uma réplica integral em italiano contemporâneo, embora sem o rico aparato de notas ali presente -, há de se ressaltar como esse ponto extremo (negativo) atingido pela recepção de Machado na Itália não faz, no fundo, senão confirmar o quão próximas se encontram as suas retraduções do terrain vague das não traduções, pelo menos em termos de aportes concretos ao conhecimento do autor, sendo, afinal, as duas faces da mesma moeda (no sentido em que, com as oportunas exceções, ler hoje as novas versões dos romances maiores não implica necessariamente ler versões melhores, nem do ponto de vista do texto nem do paratexto - repare-se bem: não estou dizendo que se trata de versões "piores", à exclusão, talvez, de um caso ou dois. Estou somente

\footnotetext{
${ }^{23}$ Tomo aqui emprestado o rótulo inteligentemente proposto por Torres (2008, p. 34), limitando-me apenas a conferir-lhe uma maior extensão semântica. No que tange aos objetos extensionalmente cobertos por essa minha recategorização, se é verdade que as adaptações e as paráfrases já constituem modalidades tradutórias reconhecidas e definidas, é igualmente verdade que a sua delimitação intenSional, em termos graduais (até que ponto, por exemplo, uma tradução é uma tradução livre, muito livre ou uma paráfrase?), nem sempre se torna uma tarefa fácil, podendo portanto ser executada apenas a negativo.
} 
dizendo que são versões diversas, cuja diversidade, porém, nem sempre redunda em progressos epistemológicos autênticos).

Daí a importância de repensar a história das traduções machadianas na Itália como um todo feito também de vazios, os quais, exatamente da mesma forma das "categorias vazias" em linguística, longe de serem inexistentes e, portanto, irrelevantes, testemunham, ao contrário, a presença de lugares a serem preenchidos para tornar significante o inteiro conjunto, de que, com efeito, constituem a contraimagem ao invés de uma simples negação. Pode ser que excepcionalmente alguns desses vazios se transformem em plenos, mas, conforme nos lembra Moretti (2005, p. 26), tais exceções não vão mudar a inércia do sistema, assim como a publicação de Memorial de Aires em 1986 (depois reeditado em 2009) e a de Helena em 2006 não deram azo a nenhuma desejável inversão de tendência na ideologia da canonização italiana do Bruxo do Cosme Velho.

Será só, então, quando as atuais não traduções passarem a integrar, como futuras traduções, as fases desse pattern recorrente que, finalmente, um novo Machado poderá despontar até na Itália.

\section{Referências}

ASSIS, Machado. Quincas Borba. Rio de Janeiro: Livraria Garnier, 1891. ASSIS, Machado de. Memorie postume di Braz Cubas. Tradução de Mario da Silva. Milano: Corbaccio, 1928.

ASSIS, Machado de. Memorie postume di Braz Cubas. Tradução de Giuseppe Alpi. Lanciano: Carabba, 1929.

ASSIS, Machado de. Gioachin Borba. L'uomo o il cane? Tradução de Giuseppe Alpi. Milano: Alberto Corticelli Editore, 1930.

ASSIS, Machado de. La fortuna di Rubiano. Tradução de Giuseppe Alpi. Milano: Alberto Corticelli Editore, 1934.

ASSIS, Machado de. Memorie dall 'aldilà. Tradução de Laura Marchiori. Milano: Rizzoli Editore, 1953.

ASSIS, Machado de. Don Casmurro. Tradução de Liliana Borla. Roma: Fratelli Bocca Editori, 1954.

ASSIS, Machado de. Don Casmurro. Tradução de Laura Marchiori. Milano: Rizzoli Editore, 1958.

ASSIS, Machado de. Quincas Borba. Tradução de Laura Marchiori. 
Milano: Rizzoli Editore, 1967.

ASSIS, Machado de. Memorie postume di Brás Cubas. Tradução de Rita Desti. Torino: UTET, 1983.

ASSIS, Machado de. Memoriale di Aires. Tradução de Giuliana Segre Giorgi. Torino: Il Quadrante, 1986.

ASSIS, Machado de. Don Casmurro. Tradução de Gianluca Manzi e Léa Nachbin. Roma: Fazi Editore, 1997.

ASSIS, Machado de. Marcela mi amò per quindici mesi e undicimila scudi, niente meno. Tradução de Silvia Marianecci. Roma: Azimut, 2005. ASSIS, Machado de. Dom Casmurro. Tradução de Guia Boni. Cagliari: Fabula, 2006a.

ASSIS, Machado de. Helena. Tradução de Carla Cirillo. Napoli: Liguori, 2006b.

ASSIS, Machado de. Memoriale di Aires. Tradução de Giuliana Segre Giorgi. Torino: Lindau, 2009a.

ASSIS, Machado de. Quincas Borba. Tradução de Elena Tantillo. Viterbo: Edizioni Sette Città, 2009b.

ASSIS, Machado de. Gioachin Borba. L'uomo o il cane? Tradução de Valentina Manzo. Milano: Mursia, 2012.

BERMAN, Antoine. A tradução e a letra ou o albergue do longínquo. Rio de Janeiro: 7Letras, 2007.

DESTI, Rita. Introduzione. In: ASSIS, Machado de. Memorie postume di Brás Cubas. Tradução de Rita Desti. Torino: UTET, 1983. p. III-XI.

DUARTE, João Ferreira. The politics of non-translation: a case study in Anglo-Portuguese relations. TTR: Traduction, Terminologie, Rédaction, v. 13, n. 1, p. 95-112, 2000.

ECO, Umberto. Quase a mesma coisa. Experiências de tradução. Rio de Janeiro: BestBolso, 2011.

MOREIRA, Paulo. O lugar de Machado de Assis na República Mundial das Letras. Machado de Assis em linha, ano 2, n. 4, p. 96-107, dez. 2009. Disponível em: <http://machadodeassis.net/download/numero04/ num04artigo05.pdf $>$. Acesso em: 25 mar. 2016. 
MORETTI, Franco. La letteratura vista da lontano. Torino: Einaudi, 2005.

MULINACCI, Roberto. Apontamentos para uma geopolítica da tradução no século XXI. Cadernos de Tradução, Florianópolis, v. 35, n. 1, p. 1035, 2015.

OLMI, Alba. Metodologia crítica da tradução literária: duas versões italianas de Dom Casmurro. Santa Cruz do Sul, SC: EDUNISC, 2001.

RIBEIRO, Gabriela Castelo Branco. Tradução e localização de software e outros produtos: audiovisual ou multimídia. Cadernos de Tradução, Florianópolis, v. 16, n. 2, p. 231-250, 2005.

SALOMÃO, Sônia Netto. Machado de Assis em tradução italiana: sistema retórico e códigos de época entre duas línguas e duas culturas. Studi Portoghesi e Brasiliani, Roma, v. XIII, p. 25-36, 2011.

SALOMÃO, Sônia Netto. Tradução e recepção de Machado de Assis na Itália: a função dos paratextos. In: SALOMÃO, Sonia Netto; MARCHIS, Giorgio de; CELANI, Simone (Org.). Italia, Portogallo, Brasile: un incontro di storia, lingua e letteratura attraverso i secoli. Roma: Nuova Cultura, 2014. p. 21-34.

SERUYA, Teresa. Contributos para uma história da tradução em Portugal. In: REICHMANN, Tinka; STRÄTER, Thomas (Org.). Übersetzen tut not-traduzir é preciso. Contribuições para a teoria e prática da tradução nos mundos lusófono e germanófono. Berlin: Edition Tranvía, 2013. p. 13-31.

TORRES, Marie-Hélène Catherine. Tradução da cultura: literatura brasileira traduzida em francês. In: GUERINI, Andréia; TORRES, Marie; COSTA, Walter Carlos (Org.). Literatura traduzida \& literatura nacional. Rio de Janeiro: 7Letras, 2008. p. 31-38.

TORRES, Marie-Hélène Catherine. Traduzir o Brasil literário. Paratexto e discurso de acompanhamento. Tubarão: Copiart Editora, 2011. v. 1.

VENUTI, Lawrence. Scandals of translation. Towards an ethics of difference. London, New York: Routledge, 1998. 
